\title{
Illusions, Delusions, and Your Backwards Bayesian Brain: A Biased Visual Perspective
}

\author{
Richard T. Born ${ }^{a}$ Gianluca M. Bencomo ${ }^{b}$ \\ ${ }^{a}$ Department of Neurobiology, Harvard Medical School, Boston, MA, USA; ${ }^{b}$ Department of Computer Science, \\ Whittier College, Whittier, CA, USA
}

\section{Keywords}

Cerebral cortex - Dopamine - Neuromodulators ·

Schizophrenia $\cdot$ Sensory systems $\cdot$ Vision

\begin{abstract}
The retinal image is insufficient for determining what is "out there," because many different real-world geometries could produce any given retinal image. Thus, the visual system must infer which external cause is most likely, given both the sensory data and prior knowledge that is either innate or learned via interactions with the environment. We will describe a general framework of "hierarchical Bayesian inference" that we and others have used to explore the role of cortico-cortical feedback in the visual system, and we will further argue that this approach to "seeing" makes our visual systems prone to perceptual errors in a variety of different ways. In this deliberately provocative and biased perspective, we argue that the neuromodulator, dopamine, may be a crucial link between neural circuits performing Bayesian inference and the perceptual idiosyncrasies of people with schizophrenia.

(c) 2021 S. Karger AG, Basel
\end{abstract}

\section{Introduction}

\section{Vision as Perceptual Inference}

For any given 2-dimensional (2D) projection on the retina (Fig. 1, gray parallelogram), there is an infinitude of possible 3D objects that could have produced that projection, only 2 of which are shown in the figure. Given this insufficiency of the visual stimulus alone, it should not be surprising that visual systems have evolved a number of mechanisms to resolve the ambiguity. For example, most animals, including humans, have 2 eyes that are laterally separated, and a comparison of the corresponding images from the 2 different viewpoints can be used to gain $3 \mathrm{D}$ information, a process known as "stereopsis" [Ponce and Born, 2008]. In addition, the comparison of successive "snap-shots" taken by the visual system as either the object or the observer moves through space can also help to disambiguate a scene. This is what happens in the award-winning visual illusion of "impossible motion" [Sugihara, 2010]: the explanation for why the balls seem to roll uphill is revealed as the camera angle is rotated. However, the initial misperception of the geometry of the apparatus and the resulting motion illusion reveals a third important mechanism: the visual system determines what is the most likely $3 \mathrm{D}$ cause of the $2 \mathrm{D}$ image, by combining 


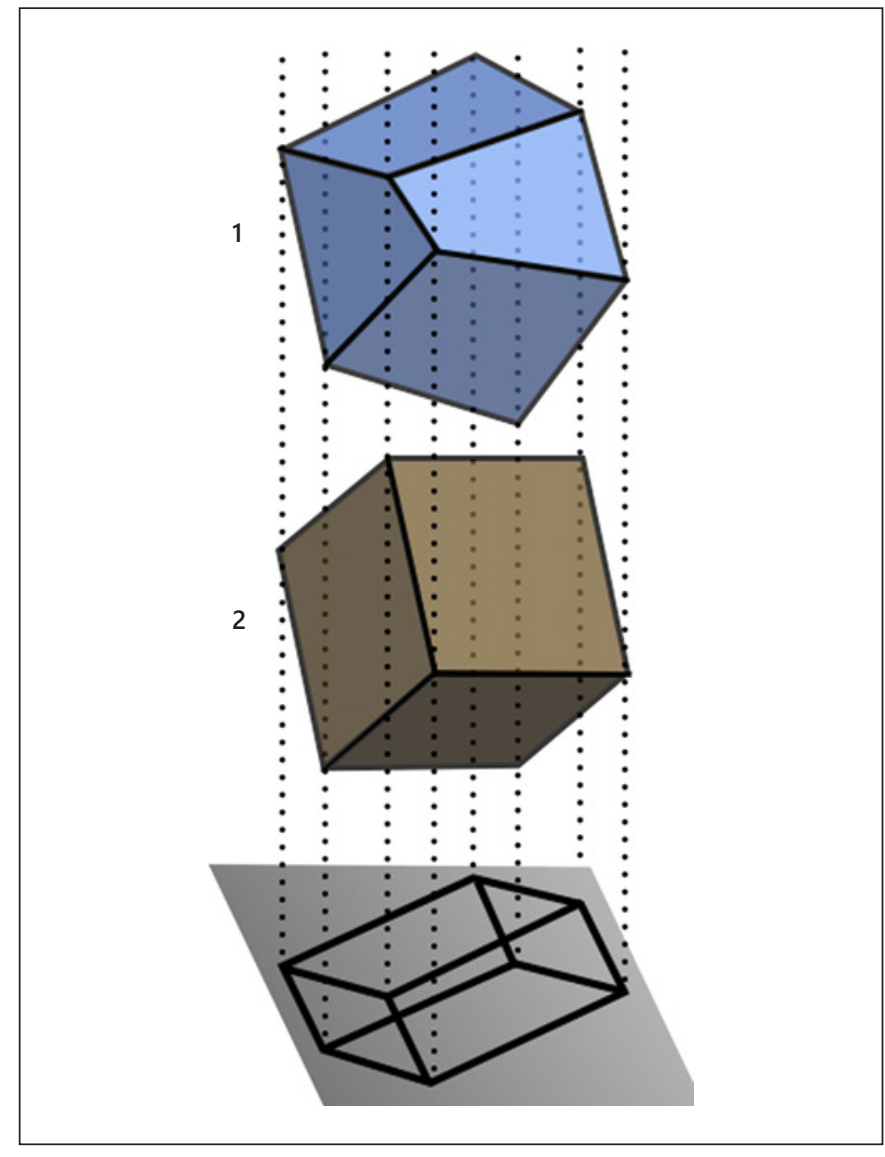

Fig. 1. Ambiguity of sensory information. Two very different $3 \mathrm{D}$ objects can produce identical 2D projections onto the retina (gray box). We tend to perceive the more likely of the 2 (modified from Fiser et al. [2010]).

the ambiguous sensory data with prior knowledge. One of the more striking demonstrations of how powerful the influence of priors can be on perception is the so-called "hollow-face illusion" [also known as the "hollow-mask illusion"; Gregory, 1970]. In one version of the illusion, a rotating mask of Charlie Chaplin actually appears to reverse direction when viewed from the concave side [rayOman, 2006], a misperception due to the fact that normal human observers see the concave inside surface of the mask as convex despite both conscious knowledge and low-level visual cues to the contrary. Interestingly, patients with schizophrenia are not as susceptible to this illusion [Dima et al., 2009], a point to which we will return below.

This process of combining sensory evidence with prior knowledge to infer what object or scene is the most likely external cause is what Hermann von Helmholtz [1925] referred to as "unconscious inference." Precedence for

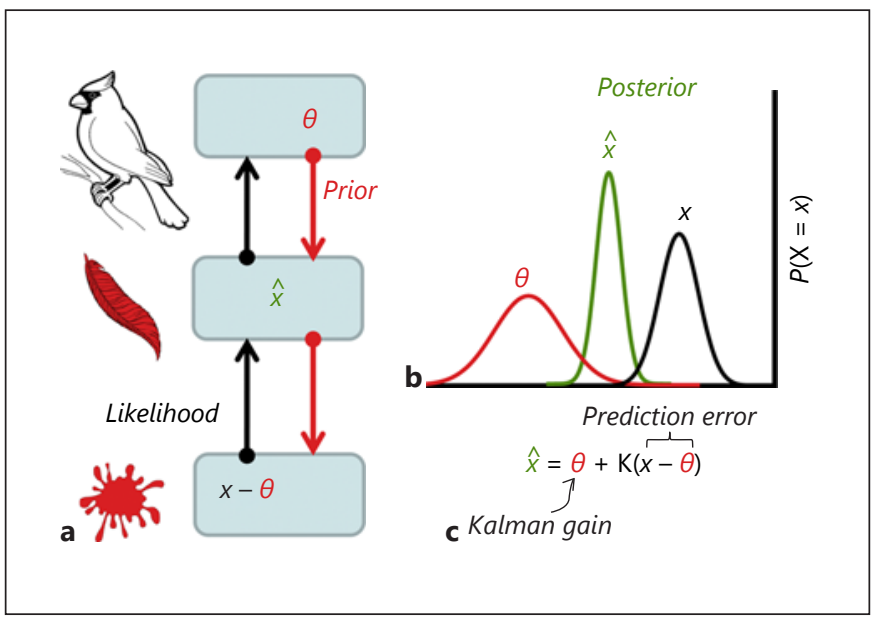

Fig. 2. Hierarchical Bayesian inference as introduced by Notredame et al. [2014]. In this scheme, each level in the hierarchy (triangles) can be thought of as a visual area in the visual cortical hierarchy. At each level, the unexpected sensory information, in the form of a "prediction error," is recombined with prior knowledge after weighting by a factor, the so-called "Kalman gain," that reflects the relative reliability of each source of information. When $\mathrm{K}$ is large, sensory evidence is favored over the prior. For example, the middle level can be thought of as computing the probability that a red feather is present, given sensory evidence for the color red and the context of a cardinal-shaped silhouette. This calculation is repeated iteratively across cortical areas and over time (inspired by Figure 4 in Notredame et al. [2014]).

the idea is most commonly attributed to Helmholtz; however, it can be found much earlier in the writings of the Arab polymath, Alhazen (Ibn al-Haytham), in the 10th century [Howard, 1996]. And despite doubts that Helmholtz was himself a Bayesian [Westheimer, 2008], in more recent times the idea has become tightly associated with so-called "Bayesian inference," because it is through Bayes' rule for inverting conditional probabilities that the inference is often performed. This topic has received much attention in the literature on vision [Weiss et al., 2002; Lee and Mumford, 2003; Yuille and Kersten, 2006; Fletcher and Frith, 2009; Moreno-Bote et al., 2011], including computational models for performing Bayesian inference with neurons and neural populations [Deneve, 2005; Doya et al., 2007; Beck et al., 2008; Ganguli and Simoncelli, 2014; Haefner et al., 2016] and the underappreciated implication this viewpoint has for the important relationship between perception and learning [Barlow, 1990; Fiser et al., 2010].

Given the abundance of literature on the topic, including several excellent reviews [Yuille and Kersten, 2006; Fletcher and Frith, 2009; Fiser et al., 2010], we will not go 
Fig. 3. A circuit for Bayesian calculations. The main player is the layer 5 pyramidal cell (red) [Bekkers 2011] which receives bottom-up inputs via its basal dendrites and top-down inputs onto its apical dendrites, an example of which is shown for the V2-to-V1 projection [Rockland and Virga, 1989]. The question mark indicates the current lack of knowledge concerning how feedback axons might interact with SST neurons, particularly in layer 1 and the superficial part of layer 2 . Inset The marked augmentation of PC neuron spiking when it receives near simultaneous inputs on its apical dendrite and cell body [Larkum et al. 1999].

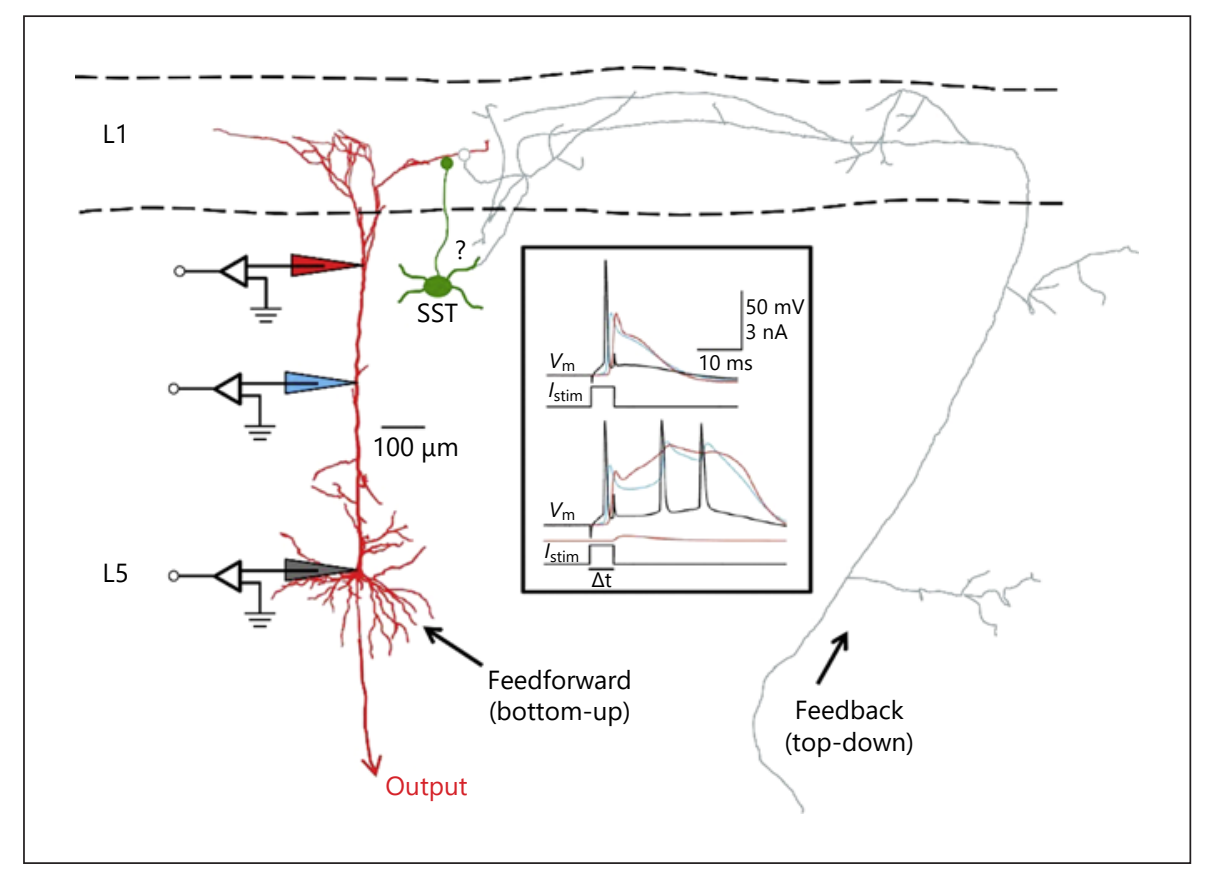

into detail here on Bayesian ideas, per se, but rather introduce a slightly different formulation put forward by Notredame et al. [2014] that incorporates the important concept of "predictive coding" into a hierarchical Bayesian scheme (Fig. 2). One key idea here is that prior knowledge is directly compared with the incoming sensory evidence to calculate a "prediction error" [Rao and Ballard, 1999], which is passed on to the next level of the hierarchy, where, after weighting by a factor that reflects the relative reliability of the prior and the likelihood [Ernst and Banks, 2002], it is combined with new prior information from above. The scheme presented in Figure 2 is greatly simplified, and it fails to adequately reflect the iterative and dynamic nature of the process after which one would expect all relevant variables (i.e., prior, prediction error, and posterior) to be represented at each level of the hierarchy with respect to that level's degree of representational abstraction. We favor this scheme, because it calls for the explicit representation of "prediction error," for which there is neurophysiological evidence (see below), and further suggests that the calculation involves corticocortical feedback. Finally, it allows for optimal combination of top-down and bottom-up information via the Kalman gain, which would naturally vary as a function of the reliability of the different sources of information. In the formula given in Figure 2c, the Kalman gain adjusts the strength of the prediction error, which can be thought of as the new (i.e., unpredicted) sensory evidence, so in- creasing the gain tips the balance away from prior beliefs and towards sensory evidence.

In the following section, we introduce a circuit motif that is widespread in the cerebral cortex and which could serve to implement Bayes-like calculations. We then describe a mechanism by which the nervous system might dynamically adjust the relative weights of evidence and priors (Kalman gain) using neuromodulators such as dopamine, and, finally, we briefly discuss some interesting sensory phenomena that occur in schizophrenia, a condition in which dysregulation of dopamine is a prominent feature.

\section{A Circuit for Integrating Top-Down with Bottom-Up Input}

The circuit depicted in Figure 3 emphasizes the role of pyramidal cells (PCs) in layer 5 of the cerebral cortex acting to compare feedforward (bottom-up) information through their basal dendrites with feedback (top-down) information via their apical dendrites, which ramify extensively in layer 1 . Under certain circumstances, the layer 5 pyramidal neurons can act as coincidence detectors in which input to the apical dendrites, when paired within a narrow time window with input near the soma, can produce bursts of action potentials, as opposed to single spikes when no distal input is supplied (Fig. 3, Inset) [Cauller, 1995; Larkum et al., 1999, 2001]. It is unclear exactly what role the coincidence-detecting aspect of the 
circuit plays in combining top-down and bottom-up inputs, but we suggest it might be important for the timing of successive cycles of updating that many models of Bayesian inference postulate [e.g., Notredame et al., 2014]. Further evidence suggests that somatostatin-containing inhibitory interneurons (SST) are another critical element of this circuit, as they can directly gate the excitability of the PC apical dendrites [Silberberg and Markram, 2007; Murayama et al., 2009; Gentet et al., 2012; Cichon and Gan, 2015; Takahashi et al., 2016], consistent with the finding that optogenetically inhibiting SST neurons, and thereby disinhibiting the PC apical dendrites, produced an increase in burst firing of layer 5 PCs [Gentet et al., 2012]. SST neurons also appear to be important elements for computing "prediction error" in the visual cortex [Adesnik et al., 2012].

The layer 5 PCs are the principal output neurons of the cortex, sending the results of their calculations to subcortical targets that are often directly involved in producing movement. As an interesting aside, the axons of most, if not all, of these layer 5 PCs send a major collateral to higher-order thalamic nuclei, such as the pulvinar, which in turn send projections back up to the cortex in what may constitute a source of efference copy [Sherman and Guillery, 2011], a signal necessary for the corollary discharge system used to predict the sensory consequences of an animal's actions (see below) [Crapse and Sommer, 2008; Sommer and Wurtz, 2008]. In the context of a Bayesian calculation, the bottom-up inputs convey the incoming sensory information (the so-called "likelihood"), the top-down inputs provide "prior" knowledge, and the output constitutes the "posterior," which can be thought of as the probability of some state of the world, given the current sensory evidence. This circuit appears to be a very generic one that operates across different areas of the cortical mantle, allowing prior knowledge (and likely other signals as well) to influence everything from visual perception [Bullier, 2001] to memory retrieval [Tomita et al., 1999] and sensorimotor coordination [Xu et al., 2012].

From this perspective, layer 1 is particularly interesting and important, as it serves as a nexus for the interactions of long-range sources of information with local cortical circuitry via the apical dendrites of pyramidal neurons and inhibitory interneurons. This layer remains a "crowning mystery" [Hubel, 1982], largely due to the fact that it contains very few neurons and most of its sources of input are remote. For example, approximately $90 \%$ of layer 1 of the primary visual cortex (V1) consists of "dark matter": synapses for which the presynaptic source can-

Illusions, Delusions, and Your Backwards Bayesian Brain not be accounted for by local neurons [Binzegger et al., 2004; Douglas and Martin, 2007]. This is because layer 1 of $\mathrm{V} 1$ receives long-range inputs from a multitude of sources, including cortico-cortical feedback from many higher visual areas [Rockland and Virga, 1989; Anderson and Martin, 2009], higher-order thalamic nuclei such as the pulvinar [Sherman and Guillery, 1996], and amygdala [Freese and Amaral, 2005], and neuromodulatory inputs such as those from the basal forebrain cholinergic [Mechawar et al., 2000] and midbrain dopamine [Seamans and Yang, 2004] neurons.

This basic circuit might account for a number of recent results in our laboratory when we reduced the top-down input to V1 in nonhuman primates (NHP) as well as some interesting similarities with the results of local circuit manipulations in rodent cortex. For example, reversibly inactivating V2/V3 (using "cryoloops" to cool regions of V2 and V3 within the lunate sulcus) of alert macaque monkeys produced reductions in the influence of visual context: surround suppression and end-stopping became significantly weaker [Nassi et al., 2013, 2014]. This result is consistent with the idea, put forward by computational neuroscientists within the framework of "predictive coding" in the visual system, that "prediction error" (in the form of contextual effects like end-stopping) is the result of interactions between top-down and bottom-up information [Rao and Ballard, 1999]. In this case, the topdown prediction from $\mathrm{V} 2$ is that most contours in natural images are extended and thus continue through most receptive fields (at least the very small ones present in V1); the spiking of an end-stopped cell in V1 signals the violation of this expectation and thus a "prediction error." This effect of feedback inactivation on surround suppression was subsequently found in the V1 of other species, including marmosets [Nurminen et al., 2018] and mice [Vangeneugden et al., 2019], and, interestingly, was very similar to the reduction in visual surround suppression observed when SST neurons were optogentically silenced locally in mouse V1 [Fig. 4b, c; Adesnik et al., 2012]. Further strengthening the possible association between cortico-cortical feedback and SST neurons, we discovered a dramatic reduction in visually evoked gamma oscillations in macaque V1 when inactivating V2/V3 [Hartmann et al., 2019], similar to that observed in mouse V1 with local SST inactivation [Fig. 4d, e; Veit et al., 2017]. A final bit of evidence connecting these results is that the strength of visually evoked gamma rhythms in monkey V1 appears to correlate with the engagement of surround suppression [Gieselmann and Thiele, 2008; Ray and Maunsell, 2011]. 


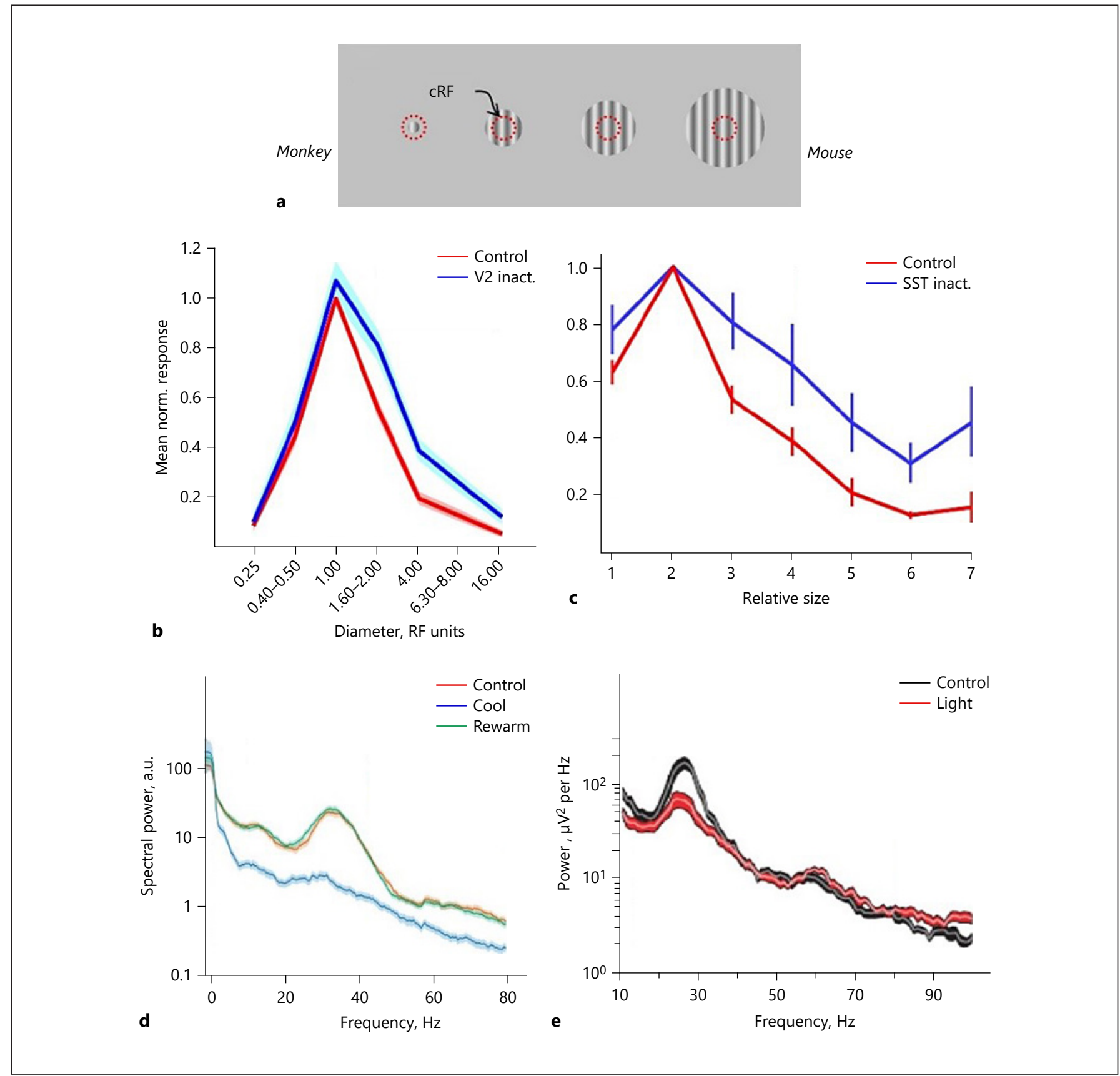

Fig. 4. Similarities between V1 effects seen after inactivation of top-down inputs in the monkey $(\mathbf{b}, \mathbf{d})$ and local inactivation of SST neurons in the mouse (c, e). For the experiments shown in $\mathbf{b}$ and c, V1 neurons were stimulated with grating patches of varying diameters (a, corresponding to the abscissas in $\mathbf{b}$ and $\mathbf{c}$ ), displaying the well-known phenomenon of surround suppression, which is weaker when V2 is reversibly inactivated (b) or SST neurons are hyperpolarized in V1 (c). For the experiments shown in $\mathbf{d}$ and

e, V1 neurons were stimulated with large, high-contrast gratings (a, right-most stimulus). The local field potential (LFP) was measured, revealing a pronounced "bump" in the gamma band ( 36 $\mathrm{Hz}$ in the monkey and $\sim 29 \mathrm{~Hz}$ in the mouse) under control conditions, which is diminished when V2 is cooled (d) or SST neurons are hyperpolarized (e). Modified from Nassi et al. [2013] (b), Adesnik et al. [2012] (c), Hartmann et al. [2018] (d), and Veit et al. [2017] (e). 
Two other results from feedback inactivation experiments are potentially accounted for by the abovementioned fact that the circuit appears to amplify top-down and bottom-up inputs that arrive within a narrow time window (Fig. 3). First, we found that statistical measures of neuronal variability (both irregularity in the timing of individual spikes and trial-to-trial variability in spike counts) were modestly reduced in V1 when V2/V3 were inactivated [Gómez-Laberge et al., 2016]. Second, we observed that the delayed component ( 100-200 ms after stimulus onset) of the visually evoked potential (VEP) in $\mathrm{V} 1$ was greatly reduced in amplitude during V2/V3 cooling [Hartmann et al., 2019]. We think that a switch from burst mode to single-spiking [Larkum et al., 1999], whether mediated by SST neurons or by a direct effect of feedback on the apical dendrites of layer 5 PCs, could account for the reduced spiking variability [Gómez-Laberge et al., 2016] and might, at least partially, explain feedback's powerful influence over the volley of recurrent activity that follows the initial feedforward response in the VEP [Hartmann et al., 2019].

Taken together, these results support an important influence of feedback on local computations in the cortex and implicate SST neurons as a possible key circuit element for mediating some of its effects. Even though no evidence exists of a particular preference for feedback axons to make direct synapses onto SST neurons [Gonchar and Burkhalter, 2003], it remains possible that such interactions take place presynaptically in layer 1 or via a multisynaptic pathway.

\section{Striking a Balance between Top-Down and Bottom- Up Information}

The sensory world is constantly changing, and this results in variability in the quality of the evidence provided by our senses. To take an obvious but important example for vision, the sun rises and sets each day, creating a wide range of illumination conditions from the high signal-tonoise (SNR) regime of full sunlight at midday, to the low SNR periods during dawn and dusk and the extremely low-signal time of night. Moreover, prior knowledge has a strong learned component [Fiser et al., 2010], so the reliability of much top-down information is also changing over the course of an animal's lifetime.

Statistical theory tells us that, to achieve "optimal" perception, i.e., to minimize the variability in our estimates of the state-of-the-world, animals should weight different sources of information in proportion to their reliability. And psychophysical experiments have shown that humans can and do integrate sensory information in this optimal way, at least under some circumstances [Ernst and Banks, 2002; Knill and Pouget, 2004; Körding and Wolpert, 2004; French and DeAngelis, 2020]. Thus, from a Bayesian perspective, our circuit (Fig. 3) would seem to require an additional level of flexibility to appropriately balance the influence of priors and sensory information as conditions change.

One candidate for mediating such changes in the balance of top-down and bottom-up inputs is the neuromodulator dopamine. We must emphasize up front that this hypothesis is highly speculative, since dopamine exerts dozens of different effects on both pyramidal cells and interneurons acting through several different families of receptors, influencing everything from synaptic release to intrinsic electrical properties [Tritsch and Sabatini, 2012]. For simplicity, we focus here on effects of the intrinsic properties of the layer 5 PCs that are central to our circuit (Fig. 3) and the role of D1 receptors, which are the most highly expressed and widespread dopamine receptors in the rodent prefrontal cortex [Tritsch and Sabatini, 2012]. For our purposes, the most interesting finding is that dopamine appears to have different effects on the apical dendrites and cell body of these neurons (Fig. 5). At the cell body and basal dendrites, D1 receptor activation increases excitability by decreasing $\mathrm{K}^{+}$currents [Yang and Seamans, 1996; Dong and White, 2003; Dong et al., 2004] as well as augmenting $\mathrm{Na}^{+}$currents [Fig. 5b; Yang and Seamans, 1996; Gorelova and Yang, 2000]. Conversely, D1 agonists decrease the excitability of apical dendrites by suppressing $\mathrm{Ca}^{++}$currents that give rise to regenerative high-threshold $\mathrm{Ca}^{++}$spikes [Yang and Seamans, 1996; Young and Yang, 2004; Kisilevsky et al., 2008; Zhou and Antic, 2012], thus decreasing both the spatial range over which the apical tuft integrates topdown information and its net influence on the cell's spikegenerating mechanism (Fig. 5a). In the context of our Bayesian calculation, increasing levels of dopamine would then serve to progressively tip the balance away from priors and in favor of the sensory evidence. In the formulation put forward in Figure 2, increasing dopamine levels would be represented by an increase in the Kalman gain.

\section{Back to Perception: Illusions and Delusions}

It is traditional in psychiatry to distinguish between "false percepts" (hallucinations or illusions) and "false beliefs" (delusions); however, as previously pointed out in the review by Fletcher and Frith [2009], from a Bayesian perspective, the two are not so different (i.e., percepts are really beliefs about the external causes of the internal states of the nervous system) and, in fact, are likely to 
Fig. 5. Differential effects of dopamine D1receptor activation on different compartments of layer 5 pyramidal cells (PCs). The D1 agonist, SKF38393, applied to cortical slices produced different effects on the apical dendrites and cell bodies of PCs. a At the apical dendrites, by attenuating the regenerative high-threshold $\mathrm{Ca}^{++}$spiking mechanism (HTS), dopamine decreased the influence of top-down inputs. b At the cell body, it increased the influence of bottom-up inputs through the combination of augmenting a slow, depolarizing influence $\left(\mathrm{gNa}^{+}\right)$and decreasing a slow, hyperpolarizing current $\left(\mathrm{gK}^{+}\right)$. Modified from Yang and Seamans [1996].

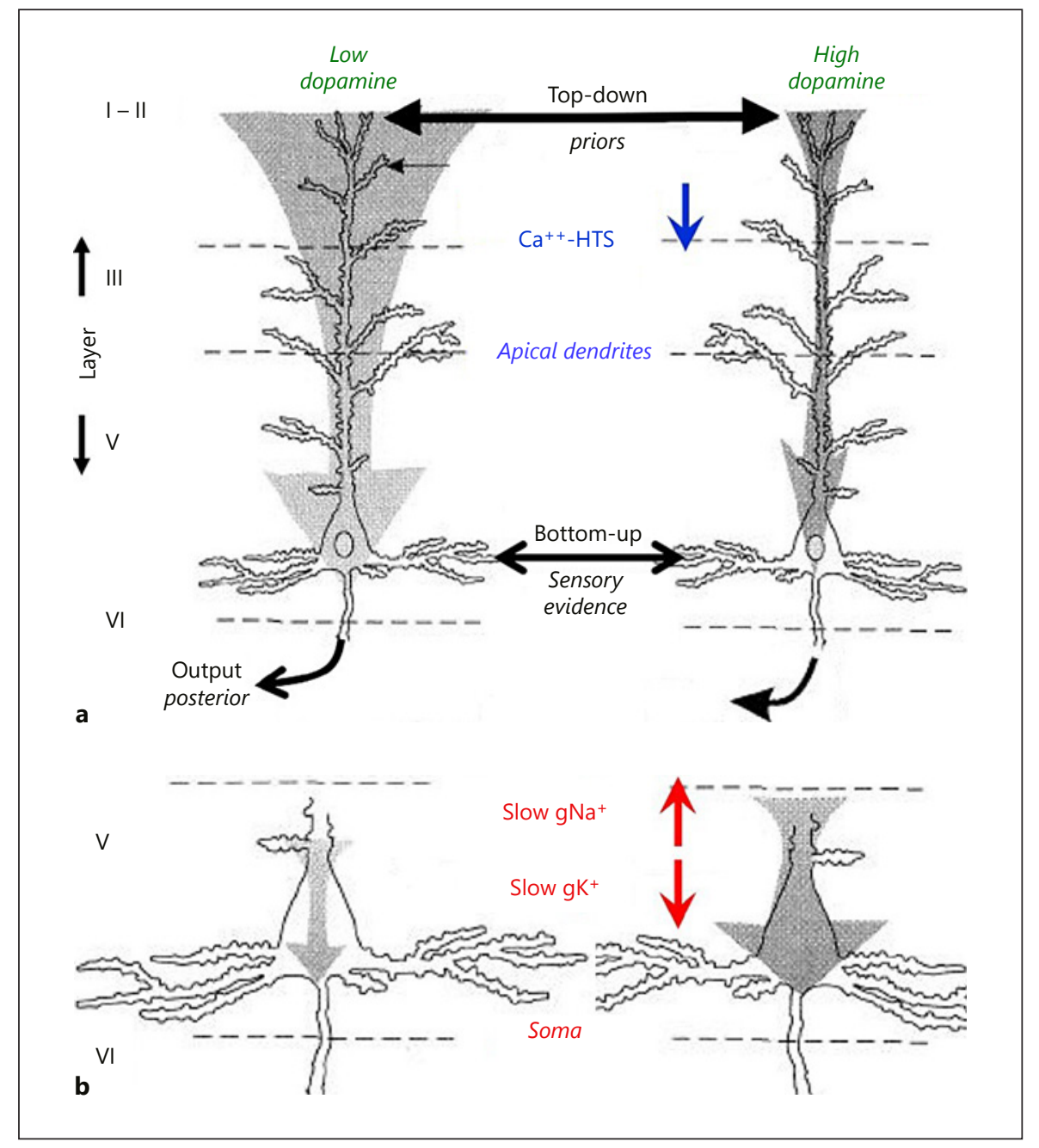

share common mechanisms. We will thus not treat them differently here, but rather focus on perceptual studies where the data are clearer and more plentiful.

If we are correct in our contention that what we see at any given moment is not just based on the bottom-up data coming in through our eyes but is also influenced by our top-down expectations, then we might predict that our visual systems would be prone to errors resulting from an imbalance in how these two sources of information are weighted. We have already encountered the powerful hollow-mask illusion, which we would interpret as the result of a very strong prior ("faces are convex") overwhelming the visual evidence. In fact, a sizeable subset of visual illusions can be interpreted in this way [Weiss et al., 2002; Notredame et al., 2014]; in most instances, the priors are not so overwhelmingly strong (at least for highcontract, low-noise stimuli), and the resulting illusions are correspondingly less spectacular. However, they are readily measurable and consistent across neurotypical observers.

One large class of visual illusions consists of those where the context in which an object appears causes systematic distortions in its appearance, a classic example of which is the Ebbinghaus illusion (Fig. 6). This particular example involves judgments of size, but the powerful influence of context has been demonstrated in virtually every visual domain, from color (simultaneous contrast; colored shadows) to orientation (tilt illusion), motion perception (Duncker illusion), and many more [Gregory, 1997; Mély et al., 2018]. Not surprisingly, many of these contextual illusions have been linked to extraclassical receptive field effects, such as surround suppression, found throughout the visual systems of NHP and other animals (Fig. 4) [Seriès et al., 2003; Mély et al., 2018]. 


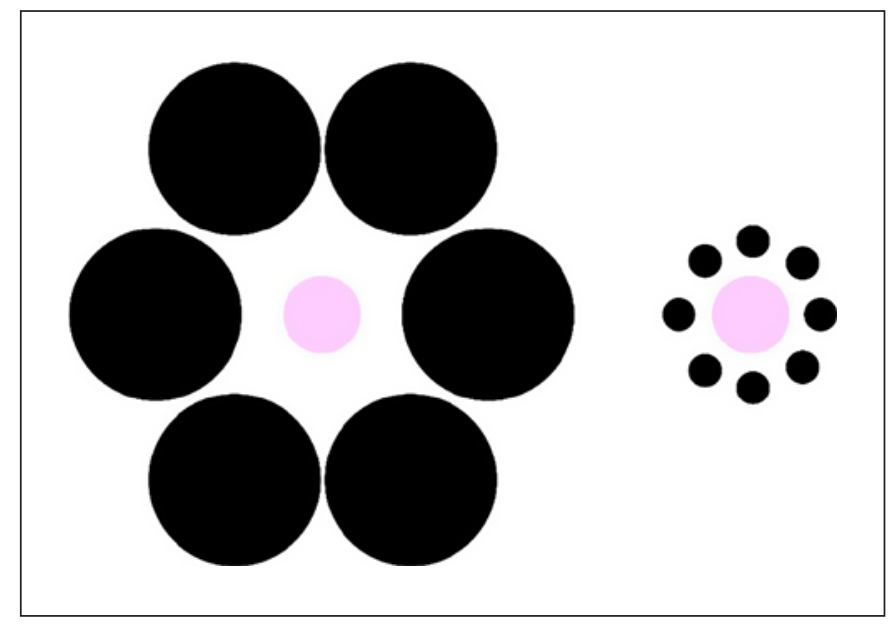

Fig. 6. The Ebbinghaus illusion. Both pink disks are actually the same size, but the different contexts cause most neurotypical observers to perceive that on the left as smaller than that on the right.

\section{Schizophrenia and Perception: Linking Dopamine to Bayesian Inference}

Multiple lines of evidence, including pharmacology, genetics, and imaging, suggest that dopamine dysregulation is a major component of the pathophysiology of schizophrenia [Howes et al., 2017; Weinstein et al., 2017; Avramopoulos, 2018]. Drugs that block dopamine receptors have long served as primary treatments for this patient population [Stępnicki et al., 2018]. Given our above speculation that dopamine may be involved in adjusting the relative weighting of sensory data and prior information, perceptual studies on people suffering from schizophrenia provide intriguing data.

A number of previous groups have interpreted schizophrenia through a Bayesian lens, focusing particularly on the important role of predictive coding in perceptual inference [Fletcher and Frith, 2009; Brown et al., 2013; Sterzer et al., 2018, 2019; Heinz et al., 2019]. As described above (Fig. 2), the essence of predictive coding is a direct comparison of prior expectations with current sensory evidence, and any differences (the "prediction errors") serve as spurs to modify internal models [i.e., update priors; Fiser et al., 2010] and can be used to calculate posteriors in hierarchical Bayesian inference schemes [Notredame et al., 2014]. Computational studies have demonstrated that predictive coding models naturally give rise to the phenomenon of "surround suppression" in sensory systems [Rao and Ballard, 1999; Schwartz et al., 2007; Spratling, 2010], and, as already described, animal studies have shown that surround suppression in the visual sys-

Illusions, Delusions, and Your Backwards Bayesian Brain tem is influenced by top-down inputs [Nassi et al., 2013, 2014; Nurminen et al., 2018; Vangeneugden et al., 2019]. It is thus particularly interesting that patients with schizophrenia appear to manifest perceptual signatures of weakened surround suppression (see below) as well as other indications that they may give decreased weight to perceptual priors.

Abnormalities in the neural representation of prior beliefs and sensory information have played an important role in theoretical treatments of the pathophysiology of schizophrenia in particular, and aberrant perceptual inference in general [Friston et al., 2016]. Nevertheless, the underlying mechanisms governing abnormal inference remain unclear. The Bayesian hierarchical predictive coding model described above (Fig. 2) provides a useful framework for understanding how prior beliefs are integrated with bottom-up information at different levels of the visual hierarchy [Felleman and Van Essen, 1991; Sterzer et al., 2018].

Perceptual studies on patients with schizophrenia generally support the idea that abnormally high dopamine levels produce an underweighting of priors. We will briefly describe two lines of evidence that support this notion: (i) the decreased susceptibility to certain visual illusions, and (ii) partial failure to incorporate sensory predictions of one's own movements, known as "corollary discharge."

As previously mentioned, a large body of literature supports the conclusion that patients with chronic schizophrenia have a lower sensitivity to expectation-driven visual illusions [Tschacher et al., 2006; Dima et al., 2009; Crawford et al., 2010; Horton and Silverstein, 2011; Keane et al., 2013; review, Notredame et al., 2014]. For example, several groups have found that the Ebbinghaus illusion (Fig. 6) is considerably weaker in people with schizophrenia [Uhlhaas et al., 2004, 2006; Bressan and Kramer, 2013]. And, as an interesting aside, it has also been reported that young children are less susceptible to the Ebbinghaus illusion [Doherty et al., 2010], a finding consistent with the above notion that some priors are learned. In fact, a host of studies has produced evidence that the influence of visual context in general, and of surround suppression (Fig. 4b, c) in particular, are reduced in people with schizophrenia [Dakin et al., 2005; Tadin et al., 2006; Yoon et al., 2009; Robol et al., 2013; Tibber et al., 2013; Yang et al., 2013]. These findings are consistent with both physiological evidence that surround suppression in V1 is influenced by top-down inputs [Nassi et al., 2013, 2014; Nurminen et al., 2018; Vangeneugden et al., 2019] and the biophysically based model suggesting that dopamine acts to diminish this influence [Fig. 5; Yang 
and Seamans, 1996]. Moreover, this diminution of the influence of top-down information appears to extend to higher-order visual priors, such as that driving the hollow-mask illusion; several studies have reported that observers with schizophrenia are much more likely to report seeing the inside of masks as concave (i.e., veridically) than are neurotypical observers [Schneider et al., 2002; Dima et al., 2009, 2010; Koethe et al., 2009]. In Dima et al. [2009], virtually none of the observers misclassified normal (i.e., convex) faces; however, the neurotypical controls overwhelmingly misperceived concave faces as convex (71 of 72 images, on average) whereas the average patient with schizophrenia misclassified only 4 of the 72 images. This striking difference supports the possibility that dysregulation of dopamine can alter the balance between prior knowledge and sensory evidence, and this in a manner that is consistent with the proposed biophysical model (Fig. 4).

It is important to note that, for the class of visual illusions described above, patients actually perform "better" than neurotypical observers. From an experimental perspective, this is convenient because it helps rule out alternative explanations such as nonspecific impairments in attention, judgment, and cognition that plague many studies in populations with neuropathology. However, we hasten to point out that these illusions are manifestations of mechanisms that are not just important, but actually optimal, for vision under normal conditions [Weiss et al., 2002]; it would therefore be a mistake to conclude that people with schizophrenia have "better vision." In fact, the persistent inappropriate balance between priors and sensory evidence, when iterated up and down an inferential hierarchy [Jardri and Denève, 2013], can ultimately lead to aberrant perception and, paradoxically, unwarrantedly high levels of confidence [Hemsley and Garety, 1986; Garety et al., 1991; Warman, 2008], resulting in fixed, delusional beliefs [Woodward et al., 2008].

A second line of evidence supporting an underweighting of priors in patients with schizophrenia comes from studies of so-called "corollary discharge" (CD), i.e., a collection of circuits that attempts to account for the sensory consequences of an animal's own motor actions [Crapse and Sommer, 2008; Sommer and Wurtz, 2008]. From the perspective of visual perception, it is obviously crucial to be able to distinguish sensory data that arises from external sources ("exafference"), such as the retinal motion produced by an approaching predator, from that produced by the movements of the observer or its sense organs ("reafference"), such as the retinal motion produced by movements of the eyes [Donaldson, 2000; Pack,
2014]. In the context of the hierarchical Bayesian inference model (Fig. 2), copies of the self-movement signals, processed through a "forward model" [Miall and Wolpert, 1996], yield a predicted sensory signal (a dynamically generated prior) that is subtracted from the actual sense data. In this case, the resulting prediction error is a sensory signal that is used to perform perceptual inference and, in addition, indicates the probability that the source of the information is external (as opposed to self-generated).

People with schizophrenia have shown deficits in this self-monitoring process across a variety of sensory modalities [Feinberg and Guazzelli, 1999; Pack, 2014]. For instance, when performing a force-matching task, patients experienced less attenuation due to self-generated forces, and out-performed controls in accurately reproducing an externally generated force [Shergill et al., 2005]. Similarly, patients revealed a diminished ability to cancel self-generated, tactile signals in a self-tickling paradigm [Blakemore et al., 2000a, 2000b]. In the visual domain, people with schizophrenia appear to lack the neural signals found in neurotypical observers, indicating discrepancies in visual feedback from performed motor sequences [Leube et al., 2010] and showing higher perceptual thresholds for detecting such incongruent visual feedback [Synofzik et al., 2010]. Further evidence of weakened $\mathrm{CD}$ in schizophrenic patients came from studies that found a decreased ability to integrate eye movement-related signals into the perception of visual motion [Thaker et al., 1999] and location [Richard et al., 2014]. Interestingly, a failure of CD might also contribute to the auditory hallucinations frequently experienced by people suffering from schizophrenia [Ford and Mathalon, 2005, and references therein]. As noted above, the comparison between experienced sensory stimuli and those predicted from internal models constitutes an important mechanism by which humans and other animals determine which are "self" and which are "other." This opens the possibility that deficits in the self-attribution of internal speech (i.e., many forms of "thinking") may be misperceived as external voices.

In sum, a considerable body of evidence suggests that patients with schizophrenia have abnormalities in how they integrate priors with sensory information. We have emphasized the literature supporting "weak priors" in schizophrenia, but readers should be aware that other investigators have argued for an overweighting of priors in schizophrenia [Benrimoh et al., 2018; Cassidy et al., 2018; Corlett et al., 2019]. And still others have adduced evidence of stronger cognitive priors but weaker perceptual 
ones [Schmack et al., 2013, 2015]. For lower-level influences, such as contextual visual illusions and corollary discharge, the preponderance of evidence clearly supports a decreased influence of priors in this population. However, one should keep in mind that the same neuromodulator can have different, even opposing, effects on different circuits, the "push/pull" role of dopamine on the striatal "direct/indirect" pathways via different dopamine receptor subtypes being a prime example [Albin et al., 1989; Kravitz et al., 2010]. Therefore, results that seem to be in conflict may be reconciled with a more detailed knowledge of these circuits and how they are modulated.

\section{Closing Remarks and Future Directions}

This has been an admittedly biased review of several different bodies of literature, perhaps illustrating the pitfalls inherent in overly strong priors. Our aim from the start was to be provocative and, whether the ideas presented here are absolutely correct in their detail is less important than the dialogue and future studies that we are hoping to inspire. Besides, it takes only one additional inhibitory interneuron intercalated into a circuit to completely invert the sign of a predicted effect or influence! And, as noted above, simply changing the subtype of a neuromodulator's receptor can lead to very different effects on the same circuit.

In this spirit, we close with a few thoughts on several specific areas that we think merit deeper investigation. First, at the circuit level, the mechanisms by which topdown information interacts with local circuits remain largely unknown, exacerbated by the fact that many of these interactions take place in layer 1 . While modern approaches using serial-section electron microscopy (EM) have begun to flesh out the details of local circuits [Morgan and Lichtman, 2013], layer 1 has not been amenable to traditional EM-based connectomics, because, as previously noted, the vast majority of the inputs are from distant sources. However, such distant sources might soon be identifiable in serial EM reconstructions by using recently developed methods that allow neural tracing with viral vectors carrying different genetically encoded labels that are distinguishable with EM [Cruz-Lopez et al., 2018; Zhang et al., 2019]. New, nondestructive imaging methods also promise to extend the distances over which circuits can be reconstructed at the ultrastructural level [Kuan et al., 2020].

Second, most studies on the influence of top-down information on perception and cognition have been done in humans and NHPs, where tools to study circuit mechanisms are lagging compared to those in rodent models.

Illusions, Delusions, and Your Backwards Bayesian Brain
In the future, this border zone needs to be more thoroughly investigated, both by improving our toolkit for circuit-level manipulations in NHP [Dai et al., 2015; ElShamayleh et al., 2016; Galvan et al., 2017] and seeking out meaningful touchpoints between studies on NHPs and rodents, in the spirit of Figure 4.

Third, the mechanisms by which neuromodulators influence specific cortical circuits are poorly understood; a myriad of cellular and synaptic effects have been described but understanding the overall effects will require sophisticated computational models [Seamans and Yang, 2004].

Fourth, how circuit-level influences of neuromodulators lead to changes in perception and behavior remains deeply mysterious. This is true, not only for dopamine, but other neuromodulators as well. Chief among those that seem ripe for investigation is serotonin $(5-\mathrm{HT})$, given the powerful perceptual distortions that are produced by hallucinogenic drugs, most of which are believed to act through 5- $\mathrm{HT}_{2 \mathrm{~A}}$ receptors [Nichols, 2004; GonzálezMaeso et al., 2007; Halberstadt, 2015]. The historical events [Pollan, 2019] that led to these drugs being classified as "schedule 1" made them virtually inaccessible to the scientific community for many years. Thankfully, this historical influence appears to be on the wane, and we hope that perceptual scientists will make use of this powerful set of tools for future studies on perception.

Finally, the body of literature showing a reduced susceptibility to contextual visual illusions and abnormal corollary discharge in patients with schizophrenia, while suggestive, remains difficult to interpret for a variety of reasons including the fact that most of these patients are on a variety of psychoactive medications, are often condemned by their illness to extremely difficult socioeconomic situations, and frequently have other neuropsychiatric diagnoses. In this regard, several studies showing diminished topdown perceptual effects in the normal population that correlate with "cognitive-perceptual schizotypal traits" [Teufel et al., 2010; Bressan and Kramer, 2013] seem particularly promising, particularly given the possibility of conducting large-scale psychophysical studies online, using tools such as Amazon's "Mechanical Turk" [Rajalingham et al., 2015; de Leeuw and Motz, 2016].

There is a tremendous gap between the conceptual simplicity of Bayesian inference and our understanding of the neural mechanisms that might implement it. Even such seemingly basic questions as how neural systems represent probability remain unsettled [Beck et al., 2008; Ma and Jazayeri, 2014; Haefner et al., 2016; Walker et al., 2020]. The situation might seem hopeless. Connectomics 
has revealed seemingly Byzantine cortical circuitry [Bock et al., 2011] which can adopt a variety of different functional modes under the influence of multiple systems of neuromodulators [Bargmann and Marder, 2013], each having scores of effects at different levels of the circuit [Seamans and Yang, 2004; Tritsch and Sabatini, 2012]. While new experimental tools to probe circuit function are surely part of the solution, ultimately, what is most needed are synthetic computational models, i.e., models that themselves represent the consensus of an entire modeling community [Bower, 2015], which can integrate results across different levels of investigation into (hopefully) simpler explanations at the level of circuit motifs that perform canonical computations [Douglas and Martin, 2007; Kouh and Poggio, 2008; Carandini and Heeger, 2011; Miller, 2016] in the service of behavioral goals [Krakauer et al., 2017].

\section{Acknowledgments}

R.T.B. wishes to thank Dr. Michael Starnbach for shelter, support, and inspiration during the Covid-19 pandemic.

\section{Statement of Ethics}

This is a review/opinion article and reports no new, original research. No experiments involving humans or other animals were performed. The authors declare that their contribution complies with internationally accepted standards for research practice and reporting.

\section{Conflict of Interest Statement}

The authors have no conflicts of interest to declare.

\section{Funding Sources}

The writing of this article was supported by NIH R01 EY11379 and funds from the Edward R. and Anne G. Lefler Foundation and the Goldenson Family Research Fund.

\section{Author Contributions}

Both authors contributed to the writing and editing of this review article.

\section{References}

Adesnik H, Bruns W, Taniguchi H, Huang ZJ, Scanziani M. A neural circuit for spatial summation in visual cortex. Nature. 2012 Oct; 490(7419):226-31.

Albin RL, Young AB, Penney JB. The functional anatomy of basal ganglia disorders. Trends Neurosci. 1989 Oct;12(10):366-75.

Anderson JC, Martin KA. The synaptic connections between cortical areas V1 and V2 in macaque monkey. J Neurosci. 2009 Sep;29(36) 11283-93.

Avramopoulos D. Recent Advances in the Genetics of Schizophrenia. Mol Neuropsychiatry. 2018 Jun;4(1):35-51.

Bargmann CI, Marder E. From the connectome to brain function. Nat Methods. 2013 Jun; 10(6): 483-90.

Barlow H. Conditions for versatile learning, Helmholtz's unconscious inference, and the task of perception. Vision Res. 1990;30(11): 1561-71.

Beck JM, Ma WJ, Kiani R, Hanks T, Churchland AK, Roitman J, et al. Probabilistic population codes for Bayesian decision making. Neuron. 2008 Dec;60(6):1142-52.

Bekkers JM. Pyramidal neurons. Curr Biol. 2011 Dec;21(24):R975.

Benrimoh D, Parr T, Vincent P, Adams RA, Friston K. (2018) Active Inference and Auditory Hallucinations. Comput Psychiatr. 2018 Dec; $2: 183-204$.
Binzegger T, Douglas RJ, Martin KA. A quantitative map of the circuit of cat primary visual cortex. J Neurosci. 2004 Sep;24(39):8441-53.

Blakemore SJ, Smith J, Steel R, Johnstone CE, Frith CD. The perception of self-produced sensory stimuli in patients with auditory hallucinations and passivity experiences: evidence for a breakdown in self-monitoring. Psychol Med. 2000a Sep;30(5):1131-9.

Blakemore SJ, Wolpert D, Frith C. Why can't you tickle yourself? Neuroreport. 2000b Aug; 11(11):R11-6.

Bock DD, Lee WC, Kerlin AM, Andermann ML, Hood G, Wetzel AW, et al. Network anatomy and in vivo physiology of visual cortical neurons. Nature. 2011 Mar;471(7337):177-82.

Bower JM. The 40-year history of modeling active dendrites in cerebellar Purkinje cells: emergence of the first single cell "community model”. Front Comput Neurosci. 2015 Oct;9:129.

Bressan P, Kramer P. The relation between cognitive-perceptual schizotypal traits and the Ebbinghaus size-illusion is mediated by judgment time. Front Psychol. 2013 Jun;4:343.

Brown H, Adams RA, Parees I, Edwards M, Friston K. Active inference, sensory attenuation and illusions. Cogn Process. 2013 Nov; 14(4): 411-27.

Bullier J. Feedback connections and conscious vision. Trends Cogn Sci. 2001 Sep;5(9):369-70.
Carandini M, Heeger DJ. Normalization as a canonical neural computation. Nat Rev Neurosci. 2011 Nov; $13(1): 51-62$

Cassidy CM, Balsam PD, Weinstein JJ, Rosengard RJ, Slifstein M, Daw ND, et al. A Perceptual Inference Mechanism for Hallucinations Linked to Striatal Dopamine. Curr Biol. 2018 Feb;28(4):503-514.e4.

Cauller L. Layer I of primary sensory neocortex: where top-down converges upon bottom-up. Behav Brain Res. 1995 Nov;71(1-2):163-70.

Cichon J, Gan WB. Branch-specific dendritic $\mathrm{Ca}(2+)$ spikes cause persistent synaptic plasticity. Nature. 2015 Apr;520(7546):180-5.

Corlett PR, Horga G, Fletcher PC, Alderson-Day B, Schmack K, Powers AR 3rd. Hallucinations and Strong Priors. Trends Cogn Sci. 2019 Feb; 23(2):114-27.

Crapse TB, Sommer MA. Corollary discharge across the animal kingdom. Nat Rev Neurosci. 2008 Aug;9(8):587-600.

Crawford TJ, Hamm JP, Kean M, Schmechtig A, Kumari V, Anilkumar AP, et al. The perception of real and illusory motion in schizophrenia. Neuropsychologia. 2010 Aug;48(10): $3121-7$.

Cruz-Lopez D, Ramos D, Castilloveitia G, Schikorski T. Quintuple labeling in the electron microscope with genetically encoded enhanced horseradish peroxidase. PLoS One. 2018 Jul;13(7):e0200693. 
Dai J, Ozden I, Brooks DI, Wagner F, May T, Agha NS, et al. Modified toolbox for optogenetics in the nonhuman primate. Neurophotonics. 2015 Jul;2(3):031202.

Dakin S, Carlin P, Hemsley D. Weak suppression of visual context in chronic schizophrenia [2]. Curr Biol. 2005 Oct;15(20):R822-4.

de Leeuw JR, Motz BA. Psychophysics in a Web browser? Comparing response times collected with JavaScript and Psychophysics Toolbox in a visual search task. Behav Res Methods. 2016 Mar;48(1):1-12.

Deneve S. Bayesian inference in spiking neurons. In: Saul LK, Weiss Y, Bottou L, editors. NIPS'04: Proceedings of the 17th International Conference on Neural Information Processing Systems; Dec 2004. Cambridge (MA): MIT Press; pp. 353-60.

Dima D, Dietrich DE, Dillo W, Emrich HM. Impaired top-down processes in schizophrenia: a DCM study of ERPs. Neuroimage. 2010 Sep; 52(3):824-32.

Dima D, Roiser JP, Dietrich DE, Bonnemann C Lanfermann H, Emrich HM, et al. Understanding why patients with schizophrenia do not perceive the hollow-mask illusion using dynamic causal modelling. Neuroimage. 2009 Jul;46(4):1180-6.

Doherty MJ, Campbell NM, Tsuji H, Phillips WA. The Ebbinghaus illusion deceives adults but not young children. Dev Sci. 2010 Sep;13(5): $714-21$.

Donaldson IM. The functions of the proprioceptors of the eye muscles. Philos Trans R Soc Lond B Biol Sci. 2000 Dec;355(1404):1685-754.

Dong Y, Cooper D, Nasif F, Hu XT, White FJ. Dopamine modulates inwardly rectifying potassium currents in medial prefrontal cortex pyramidal neurons. J Neurosci. 2004 Mar; 24(12):3077-85.

Dong Y, White FJ. Dopamine D1-class receptors selectively modulate a slowly inactivating potassium current in rat medial prefrontal cortex pyramidal neurons. J Neurosci. 2003 Apr; 23(7):2686-95

Douglas RJ, Martin KA. Mapping the matrix: the ways of neocortex. Neuron. 2007 Oct;56(2): 226-38.

Doya K, Ishii S, Pouget A, Rao RP. Bayesian brain: Probabilistic approaches to neural coding. MIT press; 2007.

El-Shamayleh Y, Ni AM, Horwitz GD. Strategies for targeting primate neural circuits with viral vectors. J Neurophysiol. 2016 Jul;116(1):12234.

Ernst MO, Banks MS. Humans integrate visual and haptic information in a statistically optimal fashion. Nature. 2002 Jan;415(6870) 429-33.

Feinberg I, Guazzelli M. Schizophrenia-a disorder of the corollary discharge systems that integrate the motor systems of thought with the sensory systems of consciousness. Br J Psychiatry. 1999 Mar;174(3):196-204.

Felleman DJ, Van Essen DC. Distributed hierarchical processing in the primate cerebral cortex. Cereb Cortex. 1991 Jan-Feb;1(1):1-47.
Fiser J, Berkes P, Orbán G, Lengyel M. Statistically optimal perception and learning: from behavior to neural representations. Trends Cogn Sci. 2010 Mar;14(3):119-30.

Fletcher PC, Frith CD. Perceiving is believing: a Bayesian approach to explaining the positive symptoms of schizophrenia. Nat Rev Neurosci. 2009 Jan;10(1):48-58.

Ford JM, Mathalon DH. Corollary discharge dysfunction in schizophrenia: can it explain auditory hallucinations? Int J Psychophysiol. 2005 Nov-Dec;58(2-3):179-89.

Freese JL, Amaral DG. The organization of projections from the amygdala to visual cortical areas TE and V1 in the macaque monkey. J Comp Neurol. 2005 Jun;486(4):295-317.

French RL, DeAngelis GC. Multisensory neural processing: from cue integration to causal inference. Curr Opin Physiol. 2020 Aug;16:813.

Friston K, Brown HR, Siemerkus J, Stephan KE. The dysconnection hypothesis (2016). Schizophr Res. 2016 Oct;176(2-3):83-94.

Galvan A, Stauffer WR, Acker L, El-Shamayleh Y, Inoue KI, Ohayon S, et al. Nonhuman Primate Optogenetics: Recent Advances and Future Directions. J Neurosci. 2017 Nov;37(45): 10894-903.

Ganguli D, Simoncelli EP. Efficient sensory encoding and Bayesian inference with heterogeneous neural populations. Neural Comput. 2014 Oct;26(10):2103-34.

Garety PA, Hemsley DR, Wessely S. Reasoning in deluded schizophrenic and paranoid patients. Biases in performance on a probabilistic inference task. J Nerv Ment Dis. 1991 Apr; 179(4):194-201.

Gentet LJ, Kremer Y, Taniguchi H, Huang ZJ, Staiger JF, Petersen CC. Unique functional properties of somatostatin-expressing GABAergic neurons in mouse barrel cortex. Nat Neurosci. 2012 Feb;15(4):607-12.

Gieselmann MA, Thiele A. Comparison of spatial integration and surround suppression characteristics in spiking activity and the local field potential in macaque V1. Eur J Neurosci. 2008 Aug;28(3):447-59.

Gómez-Laberge C, Smolyanskaya A, Nassi JJ, Kreiman G, Born RT. Bottom-up and topdown input augment the variability of cortical neurons. Neuron. 2016 Aug;91(3):540-7.

Gonchar Y, Burkhalter A. Distinct GABAergic targets of feedforward and feedback connections between lower and higher areas of rat visual cortex. J Neurosci. 2003 Nov;23(34): 10904-12.

González-Maeso J, Weisstaub NV, Zhou M, Chan $\mathrm{P}$, Ivic L, Ang R, et al. Hallucinogens recruit specific cortical 5-HT(2A) receptor-mediated signaling pathways to affect behavior. Neuron. 2007 Feb;53(3):439-52.

Gorelova NA, Yang CR. Dopamine D1/D5 receptor activation modulates a persistent sodium current in rat prefrontal cortical neurons in vitro. J Neurophysiol. 2000 Jul;84(1):75-87.

Gregory RL. The intelligent eye. London: Weidenfeld \& Nicolson; 1970.
Gregory RL. Visual illusions classified. Trends Cogn Sci. 1997 Aug;1(5):190-4.

Haefner RM, Berkes P, Fiser J. Perceptual decision-making as probabilistic inference by neural sampling. Neuron. 2016 May;90(3): 649-60.

Halberstadt AL. Recent advances in the neuropsychopharmacology of serotonergic hallucinogens. Behav Brain Res. 2015 Jan;277:99120

Hartmann TS, Raja S, Lomber SG, Born RT. Cortico-cortical feedback from V2 exerts a powerful influence over the visually evoked local field potential and associated spike timing in V1. bioRxiv. 2019. DOI: 10.1101/792010.

Heinz A, Murray GK, Schlagenhauf F, Sterzer P, Grace AA, Waltz JA. Towards a Unifying Cognitive, Neurophysiological, and Computational Neuroscience Account of Schizophrenia. Schizophr Bull. 2019 Sep;45(5): 1092-100.

Helmholtz HV. Treatise on Physiological Optics. Optical Society of America; 1925.

Hemsley DR, Garety PA. The formation of maintenance of delusions: a Bayesian analysis. Br J Psychiatry. 1986 Jul;149(1):51-6.

Horton HK, Silverstein SM. Visual context processing deficits in schizophrenia: effects of deafness and disorganization. Schizophr Bull. 2011 Jul;37(4):716-26.

Howard IP. Alhazen's neglected discoveries of visual phenomena. Perception. 1996;25(10): 1203-17.

Howes OD, McCutcheon R, Owen MJ, Murray RM. The Role of Genes, Stress, and Dopamine in the Development of Schizophrenia. Biol Psychiatry. 2017 Jan;81(1):9-20.

Hubel DH. Cortical neurobiology: a slanted historical perspective. Annu Rev Neurosci. 1982; 5(1):363-70.

Jardri R, Denève S. Circular inferences in schizophrenia. Brain. 2013 Nov;136(Pt 11):322741.

Keane BP, Silverstein SM, Wang Y, Papathomas TV. Reduced depth inversion illusions in schizophrenia are state-specific and occur for multiple object types and viewing conditions. J Abnorm Psychol. 2013 May;122(2):506-12. Kisilevsky AE, Mulligan SJ, Altier C, Iftinca MC, Varela D, Tai C, et al. D1 receptors physically interact with $\mathrm{N}$-type calcium channels to regulate channel distribution and dendritic calcium entry. Neuron. 2008 May;58(4):557-70.

Knill DC, Pouget A. The Bayesian brain: the role of uncertainty in neural coding and computation. Trends Neurosci. 2004 Dec;27(12):7129.

Koethe D, Kranaster L, Hoyer C, Gross S, Neatby MA, Schultze-Lutter F, et al. Binocular depth inversion as a paradigm of reduced visual information processing in prodromal state, antipsychotic-naïve and treated schizophrenia. Eur Arch Psychiatry Clin Neurosci. 2009 Jun; 259(4):195-202.

Körding KP, Wolpert DM. Bayesian integration in sensorimotor learning. Nature. 2004 Jan; 427(6971):244-7. 
Kouh M, Poggio T. A canonical neural circuit for cortical nonlinear operations. Neural Comput. 2008 Jun;20(6):1427-51.

Krakauer JW, Ghazanfar AA, Gomez-Marin A, MacIver MA, Poeppel D. Neuroscience Needs Behavior: Correcting a Reductionist Bias. Neuron. 2017 Feb;93(3):480-90.

Kravitz AV, Freeze BS, Parker PR, Kay K, Thwin MT, Deisseroth K, et al. Regulation of parkinsonian motor behaviours by optogenetic control of basal ganglia circuitry. Nature. 2010 Jul;466(7306):622-6.

Kuan AT, Phelps JS, Thomas LA, Nguyen TM, Han J, Chen CL, et al. Dense neuronal reconstruction through X-ray holographic nanotomography. Nat Neurosci. 2020 Dec;23(12) 1637-43.

Larkum ME, Zhu JJ, Sakmann B. A new cellular mechanism for coupling inputs arriving at different cortical layers. Nature. 1999 Mar; 398(6725):338-41.

Larkum ME, Zhu JJ, Sakmann B. Dendritic mechanisms underlying the coupling of the dendritic with the axonal action potential initiation zone of adult rat layer 5 pyramidal neurons. J Physiol. 2001 Jun;533(Pt 2):447-66.

Lee TS, Mumford D. Hierarchical Bayesian inference in the visual cortex. J Opt Soc Am A Opt Image Sci Vis. 2003 Jul;20(7):1434-48.

Leube DT, Knoblich G, Erb M, Schlotterbeck P, Kircher TT. The neural basis of disturbed efference copy mechanism in patients with schizophrenia. Cogn Neurosci. 2010 Jun;1(2): 111-7.

Ma WJ, Jazayeri M. Neural coding of uncertainty and probability. Annu Rev Neurosci. 2014; 37(1):205-20

Mechawar N, Cozzari C, Descarries L. Cholinergic innervation in adult rat cerebral cortex: a quantitative immunocytochemical description. J Comp Neurol. 2000 Dec;428(2):30518.

Mély DA, Linsley D, Serre T. Complementary surrounds explain diverse contextual phenomena across visual modalities. Psychol Rev. 2018 Oct;125(5):769-84.

Miall R, Wolpert D. Forward Models for phyiological motor control. Neural Networks. 1996;9:1265-79.

Miller KD. Canonical computations of cerebral cortex. Curr Opin Neurobiol. 2016 Apr;37: $75-84$

Moreno-Bote R, Knill DC, Pouget A. Bayesian sampling in visual perception. Proc Natl Acad Sci USA. 2011 Jul;108(30):12491-6.

Morgan JL, Lichtman JW. Why not connectomics? Nat Methods. 2013 Jun;10(6):494500 .

Murayama M, Pérez-Garci E, Nevian T, Bock T, Senn W, Larkum ME. Dendritic encoding of sensory stimuli controlled by deep cortical interneurons. Nature. 2009 Feb;457(7233): 1137-41.

Nassi JJ, Gómez-Laberge C, Kreiman G, Born RT. Corticocortical feedback increases the spatial extent of normalization. Front Syst Neurosci. 2014 May;8:105.
Nassi JJ, Lomber SG, Born RT. Corticocortical feedback contributes to surround suppression in V1 of the alert primate. J Neurosci. 2013 May;33(19):8504-17.

Nichols DE. Hallucinogens. Pharmacol Ther. 2004 Feb;101(2):131-81.

Notredame CE, Pins D, Deneve S, Jardri R. What visual illusions teach us about schizophrenia. Front Integr Nuerosci. 2014 Aug;8:63.

Nurminen L, Merlin S, Bijanzadeh M, Federer F, Angelucci A. Top-down feedback controls spatial summation and response amplitude in primate visual cortex. Nat Commun. 2018 Jun;9(1):2281.

Pack CC. Eye movements as a probe of corollary discharge function in schizophrenia. ACS Chem Neurosci. 2014 May;5(5):326-8.

Pollan M. How to change your mind: What the new science of psychedelics teaches us about consciousness, dying, addiction, depression, and transcendence. Penguin Books; 2019.

Ponce CR, Born RT. Stereopsis. Curr Biol. 2008 Sep;18(18):R845-50.

Rajalingham R, Schmidt K, DiCarlo JJ. Comparison of Object Recognition Behavior in $\mathrm{Hu}$ man and Monkey. J Neurosci. 2015 Sep; 35(35):12127-36.

Rao RP, Ballard DH. Predictive coding in the visual cortex: a functional interpretation of some extra-classical receptive-field effects. Nat Neurosci. 1999 Jan;2(1):79-87.

Ray S, Maunsell JHR. Different origins of gamma rhythm and high-gamma activity in macaque visual cortex. PLoS Biol. 2011 9:e1000610.

rayOman (2006) Charlie Chaplin Optic Illusion. Youtube.

Richard A, Churan J, Whitford V, O'Driscoll GA, Titone D, Pack CC. Perisaccadic perception of visual space in people with schizophrenia. J Neurosci. 2014 Apr;34(14):4760-5.

Robol V, Tibber MS, Anderson EJ, Bobin T, Carlin P, Shergill SS, et al. Reduced crowding and poor contour detection in schizophrenia are consistent with weak surround inhibition. PLoS One. 2013 Apr;8(4):e60951.

Rockland KS, Virga A. Terminal arbors of individual "feedback" axons projecting from area V2 to V1 in the macaque monkey: a study using immunohistochemistry of anterogradely transported Phaseolus vulgaris-leucoagglutinin. J Comp Neurol. 1989 Jul;285(1):54-72.

Schmack K, Gòmez-Carrillo de Castro A, Rothkirch M, Sekutowicz M, Rössler H, Haynes JD, et al. Delusions and the role of beliefs in perceptual inference. J Neurosci. 2013 Aug; 33(34):13701-12.

Schmack K, Schnack A, Priller J, Sterzer P. Perceptual instability in schizophrenia: probing predictive coding accounts of delusions with ambiguous stimuli. Schizophr Res Cogn. 2015 Apr;2(2):72-7.

Schneider U, Borsutzky M, Seifert J, Leweke FM, Huber TJ, Rollnik JD, et al. Reduced binocular depth inversion in schizophrenic patients. Schizophr Res. 2002 Jan;53(1-2):101-8.
Schwartz O, Hsu A, Dayan P. Space and time in visual context. Nat Rev Neurosci. 2007 Jul; 8(7):522-35.

Seamans JK, Yang CR. The principal features and mechanisms of dopamine modulation in the prefrontal cortex. Prog Neurobiol. 2004 Sep; 74(1):1-58.

Seriès P, Lorenceau J, Frégnac Y. The "silent" surround of V1 receptive fields: theory and experiments. J Physiol Paris. 2003 Jul-Nov; 97(46):453-74.

Shergill SS, Samson G, Bays PM, Frith CD, Wolpert DM. Evidence for sensory prediction deficits in schizophrenia. Am J Psychiatry. 2005 Dec;162(12):2384-6.

Sherman SM, Guillery RW. Distinct functions for direct and transthalamic corticocortical connections. J Neurophysiol. 2011 Sep;106(3): 1068-77.

Sherman SM, Guillery RW. Functional organization of thalamocortical relays. J Neurophysiol. 1996 Sep;76(3):1367-95.

Silberberg G, Markram H. Disynaptic inhibition between neocortical pyramidal cells mediated by Martinotti cells. Neuron. 2007 Mar;53(5): $735-46$.

Sommer MA, Wurtz RH. Brain circuits for the internal monitoring of movements. Annu Rev Neurosci. 2008;31(1):317-38.

Spratling MW. Predictive coding as a model of response properties in cortical area V1. J Neurosci. 2010 Mar;30(9):3531-43.

Stępnicki P, Kondej M, Kaczor AA. Current Concepts and Treatments of Schizophrenia. Molecules. 2018 Aug;23(8):23.

Sterzer P, Adams RA, Fletcher P, Frith C, Lawrie SM, Muckli L, et al. The Predictive Coding Account of Psychosis. Biol Psychiatry. 2018 Nov;84(9):634-43.

Sterzer P, Voss M, Schlagenhauf F, Heinz A. Decision-making in schizophrenia: A predictive-coding perspective. Neuroimage. 2019 Apr;190:133-43.

Sugihara K. Impossible motion: magnet-like slopes. Youtube; 2010.

Synofzik M, Thier P, Leube DT, Schlotterbeck P, Lindner A. Misattributions of agency in schizophrenia are based on imprecise predictions about the sensory consequences of one's actions. Brain. 2010 Jan;133(Pt 1): 262-71.

Tadin D, Kim J, Doop ML, Gibson C, Lappin JS, Blake R, et al. Weakened center-surround interactions in visual motion processing in schizophrenia. J Neurosci. 2006 Nov;26(44): 11403-12.

Takahashi N, Oertner TG, Hegemann P, Larkum ME. Active cortical dendrites modulate perception. Science. 2016 Dec;354(6319):158790.

Teufel C, Kingdon A, Ingram JN, Wolpert DM, Fletcher PC. Deficits in sensory prediction are related to delusional ideation in healthy individuals. Neuropsychologia. 2010 Dec;48(14): 4169-72. 
Thaker GK, Ross DE, Buchanan RW, Adami HM, Medoff DR. Smooth pursuit eye movements to extra-retinal motion signals: deficits in patients with schizophrenia. Psychiatry Res. 1999 Nov;88(3):209-19.

Tibber MS, Anderson EJ, Bobin T, Antonova E, Seabright A, Wright B, et al. Visual surround suppression in schizophrenia. Front Psychol. 2013 Feb;4:88.

Tomita H, Ohbayashi M, Nakahara K, Hasegawa I, Miyashita Y. Top-down signal from prefrontal cortex in executive control of memory retrieval. Nature. 1999 Oct;401(6754):699-703.

Tritsch NX, Sabatini BL. Dopaminergic modulation of synaptic transmission in cortex and striatum. Neuron. 2012 Oct;76(1):33-50.

Tschacher W, Schuler D, Junghan U. Reduced perception of the motion-induced blindness illusion in schizophrenia. Schizophr Res. 2006 Jan;81(2-3):261-7.

Uhlhaas PJ, Phillips WA, Mitchell G, Silverstein SM. Perceptual grouping in disorganized schizophrenia. Psychiatry Res. 2006 Dec; 145(2-3):105-17.

Uhlhaas PJ, Silverstein SM, Phillips WA, Lovell PG. Evidence for impaired visual context processing in schizotypy with thought disorder. Schizophr Res. 2004 Jun;68(2-3):249-60.

Vangeneugden J, van Beest EH, Cohen MX, Lorteije JA, Mukherjee S, Kirchberger L, et al. Activity in Lateral Visual Areas Contributes to Surround Suppression in Awake Mouse V1. Curr Biol. 2019 Dec;29(24):4268-4275.e7.
Veit J, Hakim R, Jadi MP, Sejnowski TJ, Adesnik $\mathrm{H}$. Cortical gamma band synchronization through somatostatin interneurons. Nat Neurosci. 2017 Jul;20(7):951-9.

Walker EY, Cotton RJ, Ma WJ, Tolias AS. A neural basis of probabilistic computation in visual cortex. Nat Neurosci. 2020 Jan;23(1): 122-9.

Warman DM. Reasoning and delusion proneness: confidence in decisions. J Nerv Ment Dis. 2008 Jan; 196(1):9-15.

Weinstein JJ, Chohan MO, Slifstein M, Kegeles LS, Moore H, Abi-Dargham A. Pathway-Specific Dopamine Abnormalities in Schizophrenia. Biol Psychiatry. 2017 Jan;81(1):31-42.

Weiss Y, Simoncelli EP, Adelson EH. Motion illusions as optimal percepts. Nat Neurosci. 2002 Jun;5(6):598-604

Westheimer G. Was Helmholtz a Bayesian? Perception. 2008;37(5):642-50.

Woodward TS, Moritz S, Menon M, Klinge R. Belief inflexibility in schizophrenia. Cogn Neuropsychiatry. 2008 May;13(3):267-77.

Xu NL, Harnett MT, Williams SR, Huber D, O'Connor DH, Svoboda K, et al. Nonlinear dendritic integration of sensory and motor input during an active sensing task. Nature. 2012 Dec;492(7428):247-51.
Yang CR, Seamans JK. Dopamine D1 receptor actions in layers V-VI rat prefrontal cortex neurons in vitro: modulation of dendritic-somatic signal integration. J Neurosci. 1996 Mar; 16(5):1922-35.

Yang E, Tadin D, Glasser DM, Hong SW, Blake R, Park S. Visual context processing in schizophrenia. Clin Psychol Sci. 2013 Jan;1(1):5-15.

Yoon JH, Rokem AS, Silver MA, Minzenberg MJ, Ursu S, Ragland JD, et al. Diminished orientation-specific surround suppression of visual processing in schizophrenia. Schizophr Bull. 2009 Nov;35(6): 1078-84.

Young CE, Yang CR. Dopamine D1/D5 receptor modulates state-dependent switching of soma-dendritic $\mathrm{Ca} 2+$ potentials via differential protein kinase $\mathrm{A}$ and $\mathrm{C}$ activation in rat prefrontal cortical neurons. J Neurosci. 2004 Jan; 24(1):8-23.

Yuille A, Kersten D. Vision as Bayesian inference: analysis by synthesis? Trends Cogn Sci. 2006 Jul; 10(7):301-8.

Zhang Q, Lee WA, Paul DL, Ginty DD. Multiplexed peroxidase-based electron microscopy labeling enables simultaneous visualization of multiple cell types. Nat Neurosci. 2019 May; 22(5):828-39.

Zhou WL, Antic SD. Rapid dopaminergic and GABAergic modulation of calcium and voltage transients in dendrites of prefrontal cortex pyramidal neurons. J Physiol. 2012 Aug; 590(16):3891-911. 